\title{
A CROSS-SECTIONAL STUDY ON SOCIO-DEMOGRAPHIC PROFILE OF DIPHTHERITIC PATIENTS ADMITTED IN SIR RONALD ROSS INSTITUTE OF TROPICAL AND COMMUNICABLE DISEASES, HYDERABAD, TELANGANA
}

\author{
G. Vinod Kumar' ${ }^{1}$ Asma $^{2}$, Md. Abdul Wassey ${ }^{3}$, R. L. Lakshman Rao ${ }^{4}$, Anand Chand ${ }^{5}$
}

1 Assistant Professor, Department of Community Medicine, Gandhi Medical College.

2Senior Resident, Department of Community Medicine, Gandhi Medical College.

${ }^{3}$ Postgraduate Student, Department of Community Medicine, Osmania Medical College.

${ }^{4}$ Professor, Department of Community Medicine, Osmania Medical College.

${ }^{5}$ Assistant Professor, Department of Surgery, Osmania Medical College.

\section{BACKGROUND}

\section{ABSTRACT}

Diphtheria is an acute infectious upper respiratory tract disease caused by the exotoxin produced by the bacteria Corynebacterium diphtheriae. Diphtheria is a rare disease in developed countries and endemic disease in India. In 2013, there were about 4090 cases and 64 deaths due to diphtheria in India. Environmental factors which are responsible for higher transmission rates of this infection are overcrowded houses and poor socio-economic conditions.

The objective of this study is to assess the socio-demographic profile of patients admitted in infectious disease hospital with symptoms of diphtheria.

\section{MATERIALS AND METHODS}

Study Design- Hospital record based cross-sectional study.

Study Area- Sir Ronald Ross Institute of Tropical and Communicable Diseases, popularly known as Fever Hospital, Hyderabad, Telangana.

Study Duration- One year from November 2014 to October 2015.

Study Population- All the patients admitted with the symptoms and signs of Diphtheria during the period of 2006 - 2010.

Sample Size- Out of 4528 diphtheria case sheets available, $25 \%$ of the case sheets were selected. Hence, the sample size for the present study was 1132 rounded of to 1140 .

\section{RESULTS}

The proportion of diphtheria admissions in total hospital admission was seen to be $3.06 \%$. In this study, urban preponderance was noted in the hospital admission and majority of observed diphtheria patients were Muslims. Overcrowding, especially in nonpaediatric age group was associated with diphtheria in this study.

\section{CONCLUSION}

Primary immunisation to be strengthened by maintenance of cold chain like deep freezer, ice lined refrigerators, vaccine carrier boxes and vaccine vial monitors. DT and dT booster doses should be introduced routinely at school and college entry and taken regularly.

\section{KEYWORDS}

Diphtheria, Sir Ronald Ross Institute of Tropical and Communicable Diseases, Hospital Based Study, Socio-Demographic Profile.

HOW TO CITE THIS ARTICLE: Kumar GV, Asma, Wassey MA, et al. A cross-sectional study on socio-demographic profile of diphtheritic patients admitted in Sir Ronald Ross Institute of Tropical and Communicable Diseases, Hyderabad, Telangana. J. Evolution Med. Dent. Sci. 2018;7(04):437-440, DOI: 10.14260/jemds/2018/97

\section{BACKGROUND}

Diphtheria is an acute infectious upper respiratory tract disease caused by the exotoxin produced by the bacteria Corynebacterium diphtheriae. Diphtheria is a rare disease in developed countries and endemic disease in India. During 2012, about 4490 diphtheria cases were reported globally. In 2013, there were about 4090 cases and 64 deaths due to

'Financial or Other Competing Interest': None.

Submission 11-12-2017, Peer Review 07-01-2018,

Acceptance 13-01-2018, Published 22-01-2018.

Corresponding Author:

Dr. Asma,

Senior Resident,

Department of Community Medicine,

Gandhi Medical College, 2-2-647/230/5/3, C. E. Colony,

Bagh Amberpet, Hyderabad-13.

E-mail: asma1543@gmail.com

DOI: $10.14260 /$ jemds/2018/97 diphtheria in India. Environmental factors which are responsible for higher transmission rates of this infection are overcrowded houses and poor socio-economic conditions. ${ }^{1}$ In 2005 , India contributed to $5,826(71 \%)$ of the 8,229 diphtheria cases reported globally. Of the total cases from India, 4,161 (71\%) were from the state of Andhra Pradesh. Hyderabad, the state capital, contributed 663 (16\%) of the total cases from the state (Government of Andhra Pradesh, unpublished data). The administrative coverage of primary vaccination among children $12-23$ months of age (a performance indicator for Universal Immunisation Programme [UIP]) ranged from $98 \%$ to $100 \%$ in the city from 1995 through $2006 .^{2}$

A declining trend is observed due to increasing immunisation coverage. During 2003 - 2006 diphtheria rates in Hyderabad, India, were higher among persons 5 - 19 years of age, women and Muslims than among other groups. Vaccine was efficacious among those who received $>4$ doses. 
The proportion of the population receiving boosters was low, especially among Muslims. ${ }^{2}$

\section{Objective}

1. To assess the socio-demographic profile of patients attending infectious disease hospital with symptoms of diphtheria.

2. To describe the time trends among diphtheritic patients from 2006 - 2010.

\section{MATERIALS AND METHODS}

\section{Study Design}

Hospital based retrospective cross-sectional study.

\section{Study Area}

Sir Ronald Ross Institute of Tropical and Communicable Diseases, popularly known as Govt. Fever Hospital, Hyderabad, Telangana.

\section{Study Duration}

One year from November 2014 to October 2015.

\section{Study Population}

All the patients admitted with the symptoms and signs of Diphtheria during the period 2006 - 2010.

\section{Sample Size}

Out of 4528 diphtheria case sheets available, 25\% of the case sheets were selected. Hence, the sample size for the present study was 1132 rounded of to 1140 .

\section{Sampling Method}

Systematic random sampling technique was used and every $4^{\text {th }}$ case sheet was selected. First case of diphtheria reported in the month of January 2006 is taken as first case sheet. If the fourth case sheet was found to be absconding/ left against medical advice/ case sheets not filled completely then the next case sheet was taken as $4^{\text {th }}$ case sheet.

\section{Data Collection}

After obtaining permission from the Superintendent, Sir Ronald Ross Institute of Tropical and Communicable Diseases, the investigator had visited the hospital daily to take the case sheets from the Medical Record Section. Case sheets were bundled in a month wise and disease wise. Then the bundle of diphtheria case sheets belonging to the month of January 2006 was identified and screened. Then the first case sheet belonging to the first patient admitted was taken and numbered as no. 1 , from then every $4^{\text {th }}$ case sheet was taken, screened and information was entered in the proforma.

\section{Data Analysis}

Data was analysed using Microsoft Excel and Epi Info version 7. Descriptive statistics are mentioned and chi-square tests of significance are applied wherever required.

\section{RESULTS}

On average, 228 cases were reported every year. Among seasonal variations, highest cases were seen in February (24.4\%) followed by December (23.8\%). Lowest number of cases were in August (13.4\%) followed by June (14.6\%). It was observed that Diphtheria cases were reported more during the winter season, i.e. during the months from November to March and a decline was seen during summer months.

\begin{tabular}{|c|c|c|}
\hline \multirow{2}{*}{ Year } & \multicolumn{2}{|c|}{ Total } \\
\hline & No. & $\%$ \\
\hline 2006 & 294 & 25.79 \\
\hline 2007 & 325 & 28.51 \\
\hline 2008 & 230 & 20.18 \\
\hline 2009 & 110 & 9.65 \\
\hline 2010 & 181 & 15.88 \\
\hline Total & 1140 & 100.00 \\
\hline
\end{tabular}

In the present study $25.79 \%$ cases were reported in 2006 and $28.51 \%$ in $2007,20.18 \%$ in 2008 then the cases have decreased to $9.65 \%$ in 2009 and $15.88 \%$ in 2010 . In every year, female preponderance was seen from 2006 to 2010.

Due to improved literacy, economic status and improved treatment protocol, there was a drastic decrease in number of cases from 2009 to 2010.

The present study differed with a study conducted by PN Laha et al, where male preponderance was seen in diphtheria cases. ${ }^{3}$

\begin{tabular}{|c|c|c|c|c|c|c|}
\hline \multirow{2}{*}{$\begin{array}{c}\text { Age in } \\
\text { Years }\end{array}$} & \multicolumn{2}{|c|}{ Male } & \multicolumn{2}{c|}{ Female } & \multicolumn{2}{c|}{ Total } \\
\cline { 2 - 7 } & No. & $\%$ & No. & $\%$ & No. & $\%$ \\
\hline $0-5$ & 43 & 9.56 & 29 & 4.20 & 72 & 6.32 \\
\hline $6-10$ & 110 & 24.44 & 91 & 13.19 & 201 & 17.63 \\
\hline $11-15$ & 75 & 16.67 & 85 & 12.32 & 160 & 14.04 \\
\hline $16-20$ & 74 & 16.44 & 131 & 18.99 & 205 & 17.98 \\
\hline $21-25$ & 55 & 12.22 & 100 & 14.49 & 155 & 13.60 \\
\hline $26-30$ & 40 & 8.89 & 100 & 14.49 & 140 & 12.28 \\
\hline $31-35$ & 23 & 5.11 & 63 & 9.13 & 86 & 7.54 \\
\hline $36-40$ & 19 & 4.22 & 38 & 5.51 & 57 & 5.00 \\
\hline $41-45$ & 4 & 0.89 & 22 & 3.19 & 26 & 2.28 \\
\hline $46-50$ & 3 & 0.67 & 14 & 2.03 & 17 & 1.49 \\
\hline$>50$ & 4 & 0.89 & 17 & 2.46 & 21 & 1.84 \\
\hline Total & 450 & 39.47 & 690 & 60.53 & 1140 & 100.00 \\
\hline \multicolumn{7}{|c|}{ Table 2. Distribution of Study Subjects according } \\
to the Age and Gender \\
\hline
\end{tabular}

In the present study, it was found that $39.47 \%$ of patients were males and $60.53 \%$ were females. The age group prone to diphtheria among males was 6 - 10 years of age $(24.44 \%)$ and among females was 16 - 20 years of age (18.99\%). It is observed that incidence among males was more than females in $<15$ years of age group and it was vice versa in the $>15$ years of age group, wherein incidence among females was more than males which is in conformity with already existing standard studies.

Lahari Saikia et al found the mean age of the confirmed patients was 21.8 with Standard Deviation of 10.5 years. ${ }^{4}$ In 1954 PN Laha et al, age incidence 0 - 1 year, youngest patient was 25 days old with a male preponderance. ${ }^{5}$

PN Laha and NP Mishra observed male preponderance was seen in diphtheria cases. ${ }^{3}$ According to Basappa K under 5 children had $65 \%$ of diphtheria cases compared to older children. Equal incidence was observed between the two sexes. ${ }^{6}$ This is in contrast to the present study. 


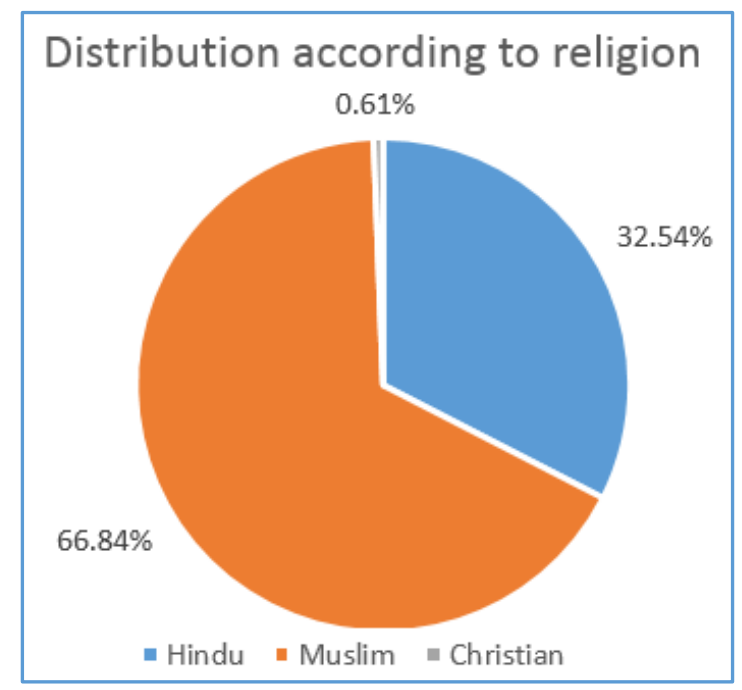

Figure 1. Distribution of Study Subjects according to Religion

Majority of study subjects 762 (66.84\%) were Muslims followed by 371 (32.54\%) were Hindus and 7 (0.61\%) were Christians.

Almost similar findings were found in a study conducted by Sailaja et al, where attack rate was highest among Muslims. ${ }^{7}$

\begin{tabular}{|c|c|c|c|c|c|c|}
\hline \multirow{2}{*}{ Immunisation } & \multicolumn{2}{|c|}{ Male } & \multicolumn{2}{c|}{ Female } & \multicolumn{2}{c|}{ Total } \\
\cline { 2 - 7 } & No. & $\%$ & No. & $\%$ & No. & $\%$ \\
\hline Complete & 7 & 3.10 & 219 & 96.90 & 226 & 19.82 \\
\hline Partial & 443 & 56.22 & 345 & 43.78 & 788 & 69.12 \\
\hline Unimmunised & 0 & 0 & 126 & 100 & 126 & 11.05 \\
\hline Total & 450 & 39.47 & 690 & 60.53 & 1140 & 100.00 \\
\hline Table 3. Distribution of Study Subjects according to \\
Immunisation Status and Gender \\
\hline
\end{tabular}

$x^{2}=299.8, d f=2, p<0.0000001$

It was found that only $19.82 \%$ of study population had complete immunisation for diphtheria and $69.12 \%$ had partial immunisation and $11.05 \%$ were unimmunised. Using chi-square test of significance, there was a significant statistical association between female gender and complete immunisation status $(\mathrm{p}<0.05)$.

Benjamin et al found in their study that the partially immunised proportion was $18 \% .^{9}$ Patowary AC and Jaiswal ON et al found that significantly lower levels of DPT coverage was observed in females in UIP district pool of India than in males. ${ }^{8}$

\begin{tabular}{|c|c|c|c|c|c|c|}
\hline \multirow{2}{*}{ Duration } & \multicolumn{2}{|c|}{ Male } & \multicolumn{2}{c|}{ Female } & \multicolumn{2}{c|}{ Total } \\
\cline { 2 - 7 } & No. & \% & No. & \% & No. & \% \\
\hline < 3 Days & 274 & 60.89 & 462 & 66.96 & 736 & 64.56 \\
\hline > 3 Days & 176 & 39.11 & 228 & 33.04 & 404 & 35.44 \\
\hline Total & 450 & 39.47 & 690 & 60.53 & 1140 & 100.00 \\
\hline \multicolumn{2}{|c|}{$\begin{array}{r}\text { Table 4. Gender Wise Distribution of Study Subjects } \\
\text { according to Onset of Disease till Admission }\end{array}$} \\
\hline
\end{tabular}

Majority 736 (64.56\%) of subjects have got admission within 3 days after onset of disease compared to 404 $(35.44 \%)$ of subjects admitted more than 3 days after the onset of disease. Female preponderance, which is statistically significant.
Laha PN et al found in their study, average duration of illness before admission was 4 days. ${ }^{5}$ Prasad MS Durga et al ${ }^{9}$ found in their study that the duration of illness prior to hospitalisation is mostly 3 days in $30.2 \%$ cases and $\geq 5$ days in $26.3 \%$ cases. $^{10}$

\begin{tabular}{|c|c|c|c|c|c|c|c|c|}
\hline \multirow{2}{*}{ Immunisation } & \multicolumn{2}{|c|}{ Hindu } & \multicolumn{2}{c|}{ Muslim } & \multicolumn{2}{c|}{ Christian } & \multicolumn{2}{c|}{ Total } \\
\cline { 2 - 8 } & No. & $\%$ & No. & $\%$ & No. & $\%$ & No. & $\%$ \\
\hline Complete & 212 & 93.81 & 7 & 3.10 & 7 & 3.10 & 226 & 19.82 \\
\hline Partial & 33 & 4.19 & 755 & 95.81 & 0 & 0.00 & 788 & 69.12 \\
\hline Unimmunised & 126 & 100 & 0 & 0.00 & 0 & 0.00 & 126 & 11.05 \\
\hline Total & 371 & 32.54 & 762 & 66.84 & 7 & 0.61 & 1140 & 100.00 \\
\hline Table 5. Distribution of Study Subjects according to \\
Immunisation Status and Religion \\
\hline
\end{tabular}

$x^{2}=980, d f=4, p<0.0000001$

It is observed that unimmunised individuals were more prevalent among Hindus 126 (100\%) than among Muslims and Christians, and the difference was statistically significant ( $p<0.0000001$ ) using chi-square test of significance.

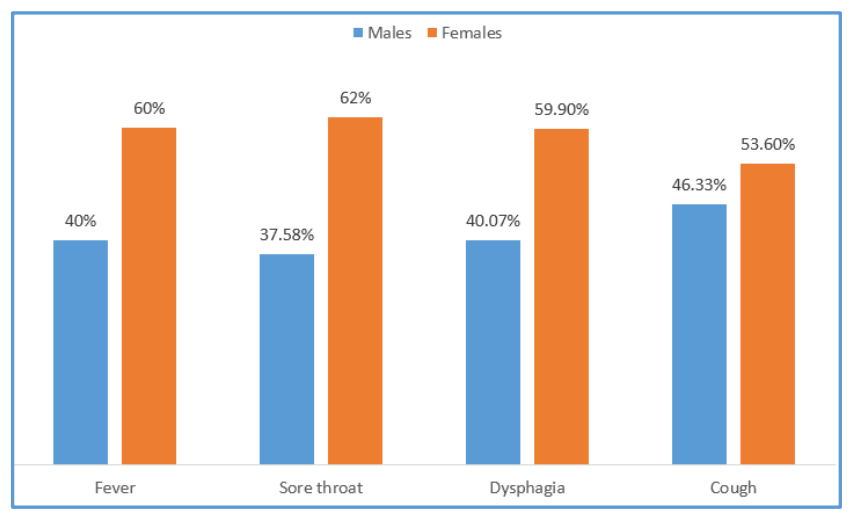

Figure 2. Distribution of Study Population according to Clinical Presentation (More than One Symptom was Present in some Study Subjects)

The most common presentation among females was sore throat (62\%) followed by fever (60\%). Among males, it was found that Cough $(46.33 \%)$ and Fever along with dysphagia $(40 \%)$ was the common presentation.

\section{DISCUSSION}

In the present study maximum cases were reported between November to March, which was similar to a study by PN Laha et al where peak incidence was seen in October and November. ${ }^{3}$

The present study findings concurred with a study conducted by Basappa $\mathrm{K}$, wherein April, May and June showed highest incidence. ${ }^{6}$

The present study findings also differed from a study by AK Chakraborthy et al, more than half of the cases occurred from July - August. ${ }^{9}$

In the present study, female preponderance was found among the study subjects which differed with a study conducted by PN Laha et al, where male preponderance was seen in diphtheria cases. ${ }^{3}$

In this study, highest number of cases among males were in age group of 6 - 10 years and among females were in the age group of 16 - 20 years. These findings were comparable to a study conducted by Lahari Saikia et al, where the mean 
age of the confirmed patients was 21.8 with Standard Deviation of 10.5 years. ${ }^{4}$ In 1954, PN Laha et al found age incidence of 0 - 1 year and the youngest patient was 25 days old with a male preponderance. ${ }^{5}$

PN Laha and NP Mishra observed male preponderance was seen in diphtheria cases. ${ }^{3}$ According to Basappa K under 5 children had $65 \%$ of diphtheria cases compared to older children. Equal incidence was observed between the two sexes. ${ }^{6}$ This is in contrast to the present study.

In the present study highest preponderance of diphtheria was found among Muslims, which concurred with a study conducted by Sailaja et al where attack rate was highest among Muslims. ${ }^{7}$

The study findings with relation to immunisation coverage and gender and immunisation status were comparable to a study by Benjamin et al, wherein the proportion of partially immunised was $18 \% .{ }^{11}$ Patowary AC and Jaiswal ON et al, found that significantly lower levels of DPT coverage was observed in females in UIP district pool of India than in males. ${ }^{8}$

The present study findings of gender and duration between onset of disease and admission was $<3$ days in majority of subjects (64.5\%). Laha PN et al found in their study, average duration of illness before admission was 4 days. ${ }^{5}$ Prasad MS and Durga et al found in their study that the duration of illness prior to hospitalisation is mostly 3 days in $30.2 \%$ cases and $\geq 5$ days in $26.3 \%$ cases. ${ }^{10}$

\section{CONCLUSION}

1. Primary immunisation to be strengthened by maintenance of cold chain like deep freezer, ice lined refrigerators, vaccine carrier boxes and vaccine vial monitors.

2. DT and dT booster doses should be introduced routinely at school and college entry and taken regularly.

3. The age shift in Diphtheria signifies success of primary immunisation as well as indicates the lack of coverage with booster doses. Thus, in the absence of booster immunisation, the older children and adults were more vulnerable to Diphtheria. The finding of the study justifies the need of booster doses at appropriate ages for effective control of Diphtheria.
4. IEC activities are to be intensified in susceptible population.

\section{Limitations of the Study}

Serological analysis for antibody estimation could not be taken up to know the immunological status.

\section{REFERENCES}

[1] Govt. of India. National Health Profile 2013, DGHS, Ministry of Health and Family Welfare, New Delhi, 2014.

[2] Bitragunta S, Murhekar MV, Hutin YJ, et al. Persistence of Diphtheria, Hyderabad, India, 2003-2006. Emerging Infectious Diseases 2008;14(7):1144-6.

[3] Laha PN, Misra NP. Diphtheria-a comparative study. Indian J Pediatr 1956;23(104):354-7.

[4] Saikia L, Nath R, Saikia NJ, et al. A diphtheria outbreak in Assam, India. Southeast Asian J Trop Med Public Health 2010;41(3):647-52.

[5] Laha PN, Srivastava JR, Agarkar SSL, et al. Diphtheria outbreak in Gwalior. IJP 1955;24(94).

[6] Basappa K. Epidemiological study of Diphtheria in retrospect. J Indian Med Assoc 1963;41(8):397-400.

[7] Bitragunta S, Murhekar MV, Hutin YJ, et al. Factors associated with persistence of diphtheria at Hyderabad, Andhra Pradesh, India. Emerg Infect Dis 2008;14(7):1144-6.

[8] Patowary AC, Jaiswal ON, Lal S, et al. Coverage evaluation survey of immunization in eleven states of India. IJCM 1990;15(4):222-6.

[9] Chakraborty AK, Das KB, Bose R. Trend of diphtheria in Calcutta. Indian J Public Health 1986;30(4):187-92.

[10] Durga PMS. Profile of diphtheria cases admitted in Sir Ronald Ross institute of tropical \& communicable diseases, Nallakunta, Hyderabad, Telangana. International Journal of Contemporary Medicine 2015;3(2):42-6.

[11] Benjamin AI, Vadhera KK, Zachariah P. Missed opportunities for immunization in children and pregnant women. Indian J Community Medicine 1990;15(4):198-206. 